\title{
Patient Perspectives on Factors Affecting Direct Oral Anticoagulant Use for Stroke Prevention in Atrial Fibrillation
}

\author{
Kristina Medlinskiene (D) ${ }^{1,2}$ \\ Susan Richardson ${ }^{3}$ \\ Beth Fylan 1,4,5 \\ Katherine Stirling ${ }^{2}$ \\ Marcus Rattray ${ }^{1,4}$ \\ Duncan Petty'
}

'Medicine Optimisation Research Group, School of Pharmacy and Medical Sciences, University of Bradford, Bradford, UK;

${ }^{2}$ Medicine Management and Pharmacy Services, Leeds Teaching Hospitals NHS Trust, Leeds, UK; ${ }^{3}$ Department of Management, Huddersfield Business School, University of Huddersfield, Huddersfield, HDI 3DH, UK; ${ }^{4}$ Wolfson Centre for Applied Health Research, Bradford, BD9 6RJ, UK; ${ }^{5}$ Bradford Institute for Health Research, NIHR Patient Safety Translational Research Centre, Bradford Teaching Hospitals NHS Foundation Trust, Bradford, BD9 6RJ, UK
Correspondence: Kristina Medlinskiene Email kristina.medlinskiene@nhs.net

\begin{abstract}
Introduction: Oral anticoagulant therapy choices for patients with atrial fibrillation (AF) expanded in the last decade with the introduction of direct oral anticoagulants (DOAC). However, the implementation of DOACs was slow and varied across different health economies in England. There is limited evidence on the patient role in the uptake of new medicines, including DOACs, apart from considering their demographic and clinical characteristics. Hence, this study aimed to address the gap by exploring the view of patients with $\mathrm{AF}$ on factors affecting DOAC use.
\end{abstract}

Methods: A qualitative study using semi-structured interviews was conducted in three health economies in the North of England. Adult patients ( $>18$ years) diagnosed with nonvalvular AF, prescribed an oral anticoagulant (vitamin $\mathrm{K}$ antagonist or DOAC), and able to give written consent were recruited. Data were collected between August 2018 and April 2019. Audio recorded interviews were transcribed verbatim and analyzed using the framework method.

Results: Four themes with eleven subthemes discussed identified factors affecting the use of DOACs. They were linked to limited healthcare financial and workforce resources, patient involvement in decision-making, patient knowledge about DOACs, safety concerns about oral anticoagulants, and oral anticoagulant therapy impact on patients' daily lives. Lack of a) opportunities to voice patient preferences and b) information on available therapy options resulted in some patients experiencing difficulties with the prescribed therapy. This was reported to cause negative impact on their daily lives, adherence, and overall satisfaction with the therapy.

Conclusion: Greater patient involvement in decision-making could prevent and resolve difficulties encountered by some patients and potentially improve outcomes plus increase the uptake of DOACs.

Keywords: uptake, new medicines, shared decision making, direct oral anticoagulants, DOACs, warfarin

\section{Introduction}

Atrial fibrillation (AF), the most frequently encountered cardiac arrhythmia, affects over 33 million people worldwide ${ }^{1,2}$ and accounts for approximately one-third of ischemic strokes. ${ }^{3} \mathrm{AF}$ is associated with a five-fold increased risk of developing stroke, ${ }^{4}$ increased cardiovascular mortality and morbidity, and increased costs to health care systems. ${ }^{5,6}$ The risk of AF-related stroke can be reduced through anticoagulation therapy ${ }^{4,5}$ with oral anticoagulants (OAs), being the mainstream therapy 
choice. The change of AF-related stroke risk calculation from CHADS2 to CHA2DS2-VASc score and removal of the recommendation for antiplatelet therapy in national and international guidelines ${ }^{4,7,8}$ further encouraged the use of OAs. $^{5}$

OA therapy choices for patients with non-valvular AF have expanded in the last decade. Vitamin $\mathrm{K}$ antagonists, predominantly warfarin, were the OAs of choice before the introduction of four direct oral anticoagulants (DOACs) ${ }^{6,9}$ DOACs have been shown to be as effective as warfarin in preventing AF-related stroke. ${ }^{9}$ DOAC therapies reduce the need for regular coagulation monitoring, have simpler dosing regimens, and fewer known drug or food interactions ${ }^{4,6,9}$ and have therefore led to a decrease of warfarin and increase of DOAC use in patients with AF. ${ }^{10}$

Despite these clinical benefits, the overall uptake of DOACs in England has been relatively low and slow. ${ }^{11}$ The average uptake was only $16.5 \%$ in 2015 with a high level of unexplained variation across different health economies in England, ranging from $4 \%$ to $70 \%$ of all OA prescribing. ${ }^{11}$ Reported barriers for DOAC use included affordability by patients or health systems, ${ }^{12-17}$ prescriber's lack of experience or knowledge of anticoagulation, DOAC use or both,,$^{12,14-16,18-20}$ and safety concerns. ${ }^{9,14,21,22}$ Other factors that are reported to influence OA prescribing decisions include patient clinical characteristics, ${ }^{12-15,19,23}$ peer prescribing practice, ${ }^{22}$ national guidelines and scientific literature, ${ }^{22}$ perceived benefits over existing warfarin therapy, ${ }^{14,22}$ and practice characteristics. $^{16,20,22,24}$

However, there is a shortage of evidence on the patient's role on the uptake of new medicines, including DOACs, apart from considering their demographic and clinical characteristics. ${ }^{25}$ Since patient involvement in medicine-related decision making is an important indicator of good quality healthcare, ${ }^{4,26,27}$ prescribing decisions, such as initiating warfarin or a DOAC should be shaped by patient preferences. Involvement of patients with $\mathrm{AF}$ in the decision-making about oral anticoagulation therapy has been reported to be minimal to none. ${ }^{28,29}$ The evidence shows that decisions in consultations were often dominated by prescribers, with patients having limited opportunities to express their preferences or choose between different therapy options. ${ }^{28,29}$ Often patients were not provided with complete information, the selection of information being influenced by prescribers' views and local protocols, to steer them towards the prescribers' or organizations' preferred option. ${ }^{28,29}$ For example, Choi et $\mathrm{al}^{30}$ found that patients initiated on warfarin were less likely to be told about DOACs in consultations, thus limiting their use.

Further evidence is needed on patients' views and experiences to gain a better understanding of the opportunities and barriers for DOAC use. Identifying these factors could help to deliver more patient-centred care to patients with $\mathrm{AF}$ and improve uptake of new medicines like DOACs. This study aimed to explore patient perspectives on factors affecting DOAC use for stroke prevention in $\mathrm{AF}$.

\section{Materials and Methods Study Design}

A qualitative study was conducted using face-to-face, semi-structured interviews. Interviews were undertaken between August 2018 and April 2019 using a developed interview guide, informed by findings of a narrative review conducted by the research team. ${ }^{29}$ The guide consisted of eight open-ended questions with associated probes and prompts exploring patients' experiences of consultation and involvement in decision-making when an OA was started, knowledge of available OAs, and views on the availability of new medicines, including DOACs, in the NHS (see Supplementary file 1). Ethics approval was granted by South Central-Oxford B Research Ethics Committee (18/SC/0284). The study was conducted in accordance with the Declaration of Helsinki.

\section{Patient and Public Involvement (PPI)}

Three people with AF taking oral anticoagulation for stroke prevention formed a PPI advisory group. Details of their involvement have been described in-depth elsewhere. ${ }^{31}$

\section{Setting and Participant Recruitment}

Patients were recruited from three health economies in the North of England. These health economies were selected due to different levels of DOAC uptake and having different mechanisms for approval and support of entry of new medicines into practice (see Supplementary file 2 for description of each health economy).

Theoretical sampling ${ }^{32,33}$ was employed to recruit eligible participants. A sample size of eight participants from each health economy (total 24) was deemed sufficient to achieve data saturation based on previous research. . $^{2,34,35}$ The recruitment of participants stopped once data saturation 
was reached (ie, the point when new interviews provided little or no change to the thematic development). ${ }^{36}$ Eligible participants were adult patients ( $>18$ years) diagnosed with non-valvular AF; prescribed an OA (vitamin $\mathrm{K}$ antagonist (eg, warfarin) or DOAC) therapy; able to give informed consent; understand written and spoken English or have a family member willing to interpret. Patients who were deemed to be inappropriate to include in the study by their direct care team (eg, end-of-life care patients, patients with dementia) were excluded.

Potential participants were identified and approached by a member of their direct care team (nurse or pharmacist) in secondary and primary care anticoagulation or arrhythmia clinics. The PPI advisory group members recruited patients from a local patient support group. Upto 30 patients were approached in each health economy and received an invitation letter and a study information leaflet with a consent form. Interested patients contacted the researcher (KM) for further information and were further assessed for eligibility. Informed written consent was obtained from all recruited participants and included publication of anonymized responses. Participants were offered reimbursement for their travel expenses if required, and a $£ 10$ high-street voucher as a token of appreciation for taking part.

\section{Data Collection}

The researcher (KM) conducted interviews at a time and place convenient to participants. Interviews were audiorecorded and transcribed verbatim.

\section{Data Analysis}

Inductive thematic analysis using the framework method ${ }^{37}$ was employed. It involves the creation of an analytical framework used to organize the data into a matrix. The method provides a clear audit trail to the analysis process as the development of themes can be linked back to the original data. Thus, potential researcher bias is minimised, ${ }^{37-39}$ increasing rigour and trustworthiness in the data analysis. ${ }^{37,40}$

An analytical framework was developed by inductive coding of five interview transcripts (KM, SR) and refined after application to another five transcripts and discussions by the research team (KM, SR, DP). The analytical framework facilitated the organization of the data and creation of five matrices, recorded using NVivo (version 11). Each transcript was re-read to summarize the data in each category of the matrix. Then, each matrix was individually cross-examined to identify key elements within each matrix, patterns, and connections across cases, and when data saturation occurred. Grouping of the identified elements led to the development of potential themes and subthemes, which were further refined by a discussion with all the authors.

\section{Results \\ Patient Characteristics}

A total of 21 patients were interviewed in the study (Table 1). The age of participants ranged from 55 to 83 years, mean 72 years. Of 21 participants, ten patients were taking warfarin, the remainder were taking a DOAC: six rivaroxaban, three apixaban, one dabigatran, and one edoxaban at the time of the interview. Two patients taking a DOAC had previously taken warfarin, and one patient experienced a switch between two different DOACs. The median (IQR) time of taking a prescribed OA was 3 years (4 weeks-7 years), warfarin 7 years (3-9 years) and DOAC 1 year (4 weeks- 4 years)

\section{Framework Analysis}

Four themes with eleven sub-themes were developed (Figure 1). The themes were: limitations of NHS resources, clinician-patient encounter, OA knowledge, and impact of therapy on daily life. Supportive verbatim quotes from participants for each theme are presented in Table 2.

\section{Theme I: Limitations of NHS Resources}

This theme presents patients' views about NHS resources, specifically limitations of these resources, and how it affected the choice of OA therapy they were offered. The theme is presented in three subthemes: medicine cost considerations, consultation time constraints, and varying local services.

\section{Medicine Cost Considerations}

Many interviewed patients were acutely aware that the NHS has a limited financial budget and needed to continually try to save money. Hence, many patients accepted the preference to use less expensive medicines as a standard practice within the NHS. Most patients perceived DOACs to be more costly than warfarin and expected warfarin to be favored over DOACs. However, some patients started on warfarin questioned if warfarin therapy was indeed a cheaper option due to the associated monitoring requirements, especially in the long term. Some even suggested that the use of DOACs would help the 
Table I Demographics of Interviewed Patients

\begin{tabular}{|c|c|c|c|c|c|c|}
\hline $\begin{array}{l}\text { Participant } \\
\text { Name* }\end{array}$ & $\begin{array}{l}\text { Health } \\
\text { Economy }\end{array}$ & Sex & Age & OAC Taken & $\begin{array}{l}\text { Duration of } \\
\text { Taking OAC }\end{array}$ & Reported Side Effects \\
\hline PI-A-D & $A$ & Male & 58 & rivaroxaban & 2 years & None \\
\hline P2-A-W & A & Male & 83 & warfarin & 15 years & Bleeding \\
\hline P3-A-W & $A$ & Male & 65 & warfarin & 6 years & None \\
\hline P4-A-W & A & Male & 70 & warfarin & 8 years & Bruising \\
\hline P5-A-W & $A$ & Male & 81 & warfarin & 23 years & None \\
\hline P6-A-D & A & Female & 82 & rivaroxaban & 4 years & None \\
\hline P7-A-W & A & Male & 76 & warfarin & 10 years & None \\
\hline P8-A-W & $A$ & Male & 78 & warfarin & 3 years & None \\
\hline P9-B-W & B & Male & 64 & warfarin & 3 years & None \\
\hline PIO-B-W & B & Female & 55 & warfarin & 2 years & Nose bleeds \\
\hline PII-B-W & B & Male & 73 & warfarin & 2 weeks & Eye bleed \\
\hline PI2-B-W & B & Female & 69 & warfarin & 9 years & None \\
\hline PI3-B-D & B & Male & 73 & edoxaban & 3 weeks & None \\
\hline PI4-C-D & C & Female & 79 & apixaban & 2 years & None \\
\hline PI5-C-D & C & Male & 72 & rivaroxaban & 4 weeks & None \\
\hline PI6-C-D & C & Male & 65 & apixaban (previously rivaroxaban, warfarin) & 4 weeks & Cold feeling and bruising with all \\
\hline PI7-C-D & C & Male & 65 & rivaroxaban (previously warfarin) & I year & Fatigue with warfarin \\
\hline PI8-C-D & C & Female & 75 & dabigatran & 5 years & Fatigue \\
\hline PI9-C-D & C & Male & 80 & rivaroxaban & 5 years & None \\
\hline P20-C-D & C & Male & 78 & rivaroxaban & 10 weeks & None \\
\hline P2I-C-D & C & Male & 77 & apixaban & 8 weeks & None \\
\hline
\end{tabular}

Notes: *Participant name included patient number (eg, $\mathrm{PI})$, health economy the patient was from (A, B, or $\mathrm{C})$, and oral anticoagulant taken (W: warfarin or direct oral anticoagulant).

Abbreviation: OAC, oral anticoagulant.

NHS to save money by releasing staff from warfarin monitoring clinics to see other patients. Nevertheless, not all patients were happy that cost may be prioritized in therapy decisions. Some patients wished therapy options were tailored to their needs by considering their health status, lifestyle, and preferences. Some said they would be willing to pay for the new, more expensive medicine if it meant a better quality of life.

\section{Consultation Time Constraints}

Many patients, when starting anticoagulation, stated the standard ten minutes allocated to a consultation with a GP was not enough to discuss therapy options. Some patients thought that asking for an explanation about medicines was wasting doctors' time. They feared becoming a burden to the system that was perceived to be already under pressure. Some patients suggested that longer consultations were needed to involve patients in the decisionmaking process. However, others were clear that having an extended consultation was not possible due to the NHS being short of the qualified personnel and overwhelmed with patients. Despite consultation constraints, some patients discussed work-around strategies. For instance, some patients booked two instead of one appointment with their GP. Some patients also experienced a variation of consultations between different GPs with some GPs, giving the time the patient needed, whereas others were stricter with the time. Some also indicated that consultations at the hospital outpatient clinics, eg, warfarin, offered more time to have an in-depth discussion than possible with GPs. Furthermore, patients taking warfarin did not expect to be informed about alternative therapy options. In their opinion, both patients and doctors, because of limited time in consultations, prioritized resolving the presenting issues rather than improving what was perceived as already working.

\section{Varying Local Services}

A few patients wondered if, in the area they live, only certain medicines were available. For instance, one patient recalled their previous experience with the NHS of availability of service depending on their geographical location. They thought that might apply to the availability of new medicines, including DOACs, as well. Some patients questioned if established local services could dictate what medicines were offered to patients. For instance, one 


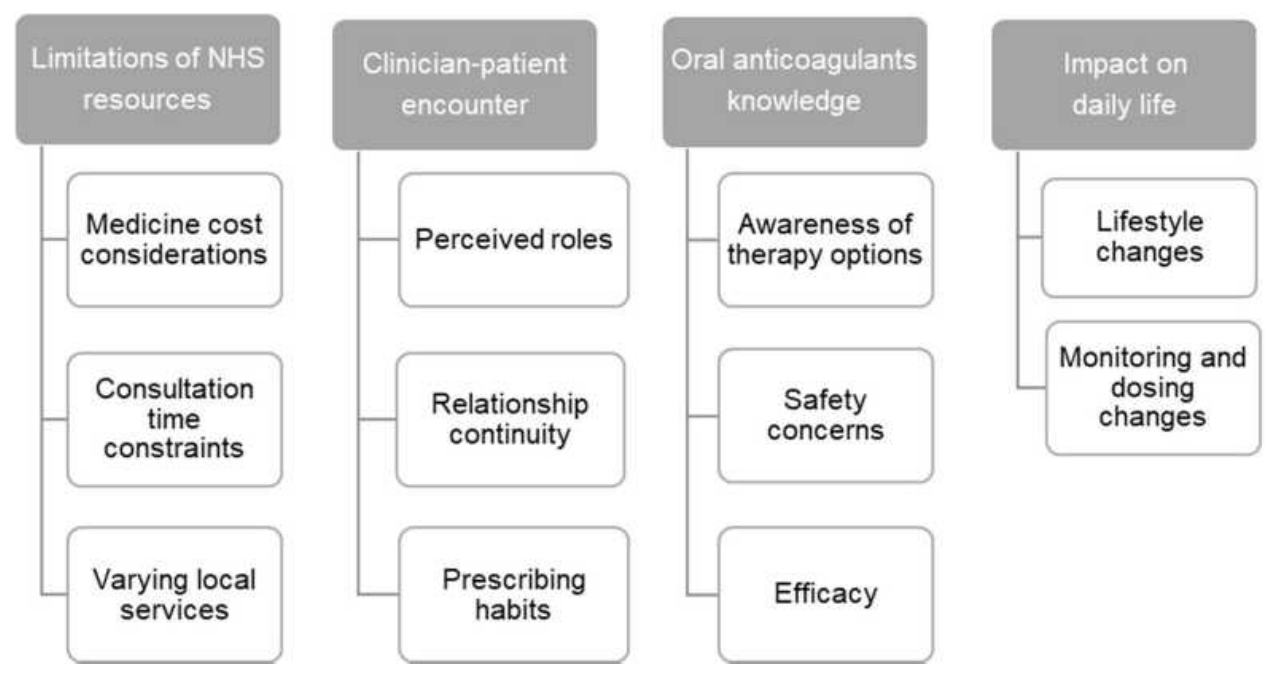

Figure I Summary of Developed Themes and Sub-Themes from the Interview Data with Patients.

patient speculated that only warfarin was offered to them because there was an established warfarin clinic at their GP practice. Another patient was given an impression by their GP that the warfarin clinic at a hospital rather than the GP or the patient made the decision which OA to prescribe.

\section{Theme 2: Clinician-Patient Encounter}

This theme describes patients' experiences and views on their interactions with the clinician and how it affected their involvement in the decision-making about therapy choices. It is presented in three subthemes: perceived roles, relationship continuity, and prescribing habits.

\section{Perceived Roles}

Some patients reflected they were brought up to accept doctors' authority. It was the clinician's role to make decisions and the patient's to tell their symptoms and follow the clinician's instructions. A few patients commented that being involved in the decision-making process had never occurred to them and said that questioning the clinician indicated a lack of respect. Also, some patients viewed that there was only a choice between accepting or refusing anticoagulation. Hence, some patients thought there was no need for their involvement, especially when only one therapy option was presented, as they would choose anticoagulation to prevent stroke. Some patients recalled being diagnosed with $\mathrm{AF}$ and started on an OA during an acute hospital admission. They described at the time feeling unwell and worried about their health and having a stroke. Hence, in these circumstances, patients did not feel it was the right time for them to get involved in the decision-making about the choice of OA therapy, and they detached themselves from participation. Most patients believed and expected that doctors would make the best and right decision tailored to their needs and circumstances. Some of these patients started on warfarin or a DOAC, had high trust in clinicians and were satisfied with little or no involvement in decision-making. In contrast, other patients wished they had an opportunity to discuss the therapy options, why they needed it, and its implications in more detail. This was particularly the case for patients who were unsatisfied with their current OA therapy, mostly warfarin. They reasoned that they should have a say in the choice of the therapy as they are going to have to live with the decision made. Some patients started on a DOAC experienced making the decision together with the doctor as they were offered more than one therapy option and an opportunity to voice their preferences. Two patients described making the decision themselves.

\section{Relationship Continuity}

Some patients described experiencing a lack of relationship continuity with their clinicians as they saw a different clinician every time, they had an appointment at GP practice. They felt that a new doctor did not know their medical history, which prevented being involved in the decisionmaking process, or having enough support when choosing between OA options. When asked, patients indicated that they prefer to see a regular doctor who knows them. Hence, they could develop a relationship with the clinician, ask questions, and consequently get involved in the discussion 
Table 2 Quotes Supporting Themes and Sub-Themes

\begin{tabular}{|c|c|c|}
\hline Theme & Subtheme & Quotes \\
\hline \multirow[t]{10}{*}{$\begin{array}{l}\text { Limitations of NHS } \\
\text { resources }\end{array}$} & \multirow[t]{3}{*}{$\begin{array}{l}\text { Medicine cost } \\
\text { considerations }\end{array}$} & $\begin{array}{l}\text { "He [GP] was clearly saying we always start with warfarin because it is affordable, the other } \\
\text { medication they are costly ... This is [warfarin] costing NHS plenty of money because when I go to } \\
\text { the clinic, I am using the time of the secretary, the time of the nurse, the material for checking, the } \\
\text { device, the paper, the time of the nurse or the pharmacist, all that is recovered from the time of ... } \\
\text { for the cost of this. For me, I just thinking about, okay, I am having every three weeks going to speak } \\
\text { with nice people, checking my condition - that's fair enough but is this looking right by the NHS? No, } \\
\text { I do not think [the] NHS [is] helping themselves prescribing this medication [warfarin] while if they } \\
\text { prescribe these medications [DOACs] will require only to take it once and forget about it, they will } \\
\text { save more than the money they save from prescribing [warfarin]." (P9-B-W) }\end{array}$ \\
\hline & & $\begin{array}{l}\text { "I mean they [NHS] are very sensitive to cost, aren't they? If you can save a bob, save it, I understand } \\
\text { that because they are always strapped for cash." (PII-B-W) }\end{array}$ \\
\hline & & $\begin{array}{l}\text { "I think the key point is there may be something better for me and I want to have that discussion and } \\
\text { if somebody said to me, 'Well you know we can't afford it on the NHS', well fine I will pay for it } \\
\text { privately. I do not mind, if that gives me something a lesser risk, a better lifestyle because to me it's } \\
\text { not the longevity it's more about quality." (P3-A-W) }\end{array}$ \\
\hline & \multirow[t]{4}{*}{$\begin{array}{l}\text { Consultation time } \\
\text { constraints }\end{array}$} & $\begin{array}{l}\text { "Well if the doctor was going to sit and offer me options and discuss the pros and cons of the } \\
\text { various medicines which might be available, then a 10-minute appointment isn't going to cut the } \\
\text { mustard is it?" (PI8-C-D) }\end{array}$ \\
\hline & & $\begin{array}{l}\text { "You know the health service is under a great deal of stress at the moment, I am okay I have not } \\
\text { died yet, I do not have anything that's affecting my lifestyle that I need to go back seeing the doctors. } \\
\text { Therefore, I do not go back, I am not going to knock on his door and say I want this or I want that, I } \\
\text { want that or whatever else. So, no I do not feel empowered to do that but l'd like to be." (P3-A-W) }\end{array}$ \\
\hline & & $\begin{array}{l}\text { "... if you went to inform the people on warfarin about a new one where would you get your } \\
\text { millions from, it would be a very expensive procedure ... If you were offering them a choice of three } \\
\text { you would need to give them the information again cost ... I mean if you have gone with something I } \\
\text { do not know pain within your stomach, you are not going to be bothered about talking about the } \\
\text { possible improvement you get from something else if it was going to detract from why you had gone } \\
\ldots \text { ". (P5-A-W) }\end{array}$ \\
\hline & & $\begin{array}{l}\text { "They say its I } 0 \text { minutes per patient. I mean I can go up to the doctors .... I can be waiting an hour } \\
\text { before I even go in. I think as timewise, as I say, all doctors are different. Some doctors like the } \\
\text { doctors up there [his GP practice], a couple of them up there, I will go in there and I will sit, and } \\
\text { they will talk and talk until I am ready to go. You have got another doctor will be in there and is } \\
\text { precise. In blah, blah .....and you are out. You are out in your I0 minutes." (P20-C-D) }\end{array}$ \\
\hline & \multirow[t]{3}{*}{$\begin{array}{l}\text { Varying local } \\
\text { services }\end{array}$} & $\begin{array}{l}\text { "Also you get the feeling why was not I offered the new stuff .....was it because there is a very well } \\
\text { established warfarin clinic at the practice every Friday and it's easy just to work with one drug rather } \\
\text { than four, I do not know ... and more you know we have done this, this is how we do things here, } \\
\text { it's warfarin and warfarin only right now ..." (P3-A-W) }\end{array}$ \\
\hline & & $\begin{array}{l}\text { ".... it's not up to you, it is up to clinic, if the clinic they see that warfarin doesn't work for you then } \\
\text { they will go and give you, they advise you to all different medication." (P9-B-W) }\end{array}$ \\
\hline & & $\begin{array}{l}\text { "... my daughter had cancer. Now when we applied for a wig, because of our postal code, she was } \\
\text { not allowed that on the National Health. But if I had gone over to the other side of town, she was } \\
\text { allowed the wig. And that is exactly the same with medicines is not it? And some of it, whether that's } \\
\text { true or what I do not know on costing and your postal codes again, if it is depending on which postal } \\
\text { code you have got you get a dearer medicine because there are cheaper medicines and dearer } \\
\text { medicines is not there?" (PI3-B-D) }\end{array}$ \\
\hline
\end{tabular}

(Continued) 
Table 2 (Continued).

\begin{tabular}{|c|c|c|}
\hline Theme & Subtheme & Quotes \\
\hline \multirow[t]{11}{*}{$\begin{array}{l}\text { Clinician-patient } \\
\text { encounter }\end{array}$} & \multirow[t]{5}{*}{ Perceived roles } & $\begin{array}{l}\text { "I think it's the history of how the NHS works, I think they are being very much a doctor this, } \\
\text { doctor that, doctor says you should do so and so, oh right so you do it. Doctor says chop my hand } \\
\text { off, okay, you know. People are not used to asking doctors questions or question that doctors might } \\
\text { not be right. Nor am I." (PII-B-W) }\end{array}$ \\
\hline & & $\begin{array}{l}\text { "It was that [warfarin] or nothing, on or off. I could have said yes and no, well yes or no did I want it } \\
\text { or not, but it would be crazy not to go onto it. "(P3-A-W) }\end{array}$ \\
\hline & & $\begin{array}{l}\text { "I like to be told you know these are the options, these are the pros, these are the cons ... I like to } \\
\text { be part of the decisions, I would prefer ... where it's almost a joint decision" (P3-A-W) }\end{array}$ \\
\hline & & $\begin{array}{l}\text { "We have both got a say, that's it discussed, you know, the pros and the cons for it and then you can } \\
\text { put your point of view forward and the consultant put his and hopefully you'll come to some mutual } \\
\text { agreement ....I think it's much more beneficial for both the consultant and myself to have a } \\
\text { discussion about it and both decide which one might be best." (PI4-C-D) }\end{array}$ \\
\hline & & $\begin{array}{l}\text { "I was not well. I was too poorly. I was happy to be in there [hospital] receiving wonderful attention } \\
\text { and I was getting some medication of what I needed ... I know that anything blood going through the } \\
\text { heart can result in a heart attack or stroke. So, I thought it's a blessing that I have been found out." } \\
\text { (P2 I-C-D) }\end{array}$ \\
\hline & \multirow[t]{3}{*}{$\begin{array}{l}\text { Relationship } \\
\text { continuity }\end{array}$} & $\begin{array}{l}\text { "I mean you go in and I see names come up, and I haven't a clue who they all are, it's different } \\
\text { doctors then next news they've gone, and there's somebody else up there." (P6-A-D) }\end{array}$ \\
\hline & & $\begin{array}{l}\text { "If you get someone that you see on a regular basis, at the other place there was someone that is } \\
\text { possibly your GP if he's not available, you see someone else, yes, when you see the same one he } \\
\text { knows what you are doing, he knows your story a bit more than the other one, the other one is } \\
\text { spending } 10 \text { minutes trying to read your information on the screen. So, the consultation is going to } \\
\text { be } 10 \text { minutes, so at the end of the story, he just says, 'Here, have this,' and he goes. Yes, obviously, it } \\
\text { makes a difference." (PI7-C-D) }\end{array}$ \\
\hline & & $\begin{array}{l}\text { "I do speak to my pharmacist because l'm very friendly with him. It's actually in the doctor's surgery, } \\
\text { and he is a nice man I spoke to him about things, and he's always advised me." (P20-C-D) }\end{array}$ \\
\hline & \multirow[t]{3}{*}{ Prescribing habits } & "It's probably the doctors not being up to date with what usage they [DOACs] are ..." (P8-A-W) \\
\hline & & $\begin{array}{l}\text { "... there is certainly from my experience this comfort with warfarin, it has been used, it has been } \\
\text { tried, we have got dozens of patients on it, we have a system set up to monitor it ..." (P3-A-W) }\end{array}$ \\
\hline & & $\begin{array}{l}\text { "... because some places the doctors they are flipping old .... I don't think some of them want to } \\
\text { pick up about new ... read about new pills ... some of them are stuck in the past” (PI-A-D) }\end{array}$ \\
\hline
\end{tabular}

(Continued)

about available therapy options. However, most patients stated that trying to see the same doctor was challenging. Only a few patients described seeing a regular doctor and experiencing good communication with them. Some patients started on warfarin described building a relationship with the pharmacists at the warfarin clinic and being able to ask them questions and therefore becoming more involved in their management of warfarin. A few patients described using a community pharmacy for additional advice or information as they had built a relationship with them.

\section{Prescribing Habits}

Despite many patients seeing doctors as experts, some patients queried prescriber knowledge and experience that could potentially affect the use of new medicines. Some patients suggested that doctors might not be aware of the latest information about available DOACs. Hence, patients would not be informed about DOACs during their consultation, and the doctor would not prescribe them. Some patients suggested that some doctors were unwilling to change their prescribing habits due to their familiarity with warfarin and the established 
Table 2 (Continued).

\begin{tabular}{|c|c|c|}
\hline Theme & Subtheme & Quotes \\
\hline \multirow[t]{12}{*}{$\begin{array}{l}\text { Oral anticoagulants } \\
\text { knowledge }\end{array}$} & \multirow[t]{5}{*}{$\begin{array}{l}\text { Awareness of } \\
\text { therapy options }\end{array}$} & $\begin{array}{l}\text { "I knew about warfarin before because I knew from acquaintances who were on warfarin and what it } \\
\text { involved." (PI8-C-D) }\end{array}$ \\
\hline & & "I have had no discussion about any of them at all. " (PIO-B-W) \\
\hline & & $\begin{array}{l}\text { "As I say just literally searching online and looking at you know what was recommended for blood } \\
\text { thinning ... you think do I really want to be taking that sort of stuff [warfarin], isn't there anything } \\
\text { better really, hasn't science brought anything else." (P3-A-W) }\end{array}$ \\
\hline & & $\begin{array}{l}\text { "When I left the hospital, I have my younger brother who is a consultant orthopaedic, he was } \\
\text { thinking well they might prescribe warfarin or some other medication where you do not need any } \\
\text { testing. So I was waiting for the hospital to send me an appointment. Then I went to hospital, } \\
\text { straight away they asked me to go to warfarin clinic ....I did not challenge it and when I had the } \\
\text { problem to get it right [INR], when I asked my GP [about the alternative to warfarin]." (P9-B-W) }\end{array}$ \\
\hline & & $\begin{array}{l}\text { "Warfarin is doing that for me so why would I change it? I'm inclined to say that if it's not broken } \\
\text { don't try to mend it and as far as I'm aware warfarin's working, so l'd leave it alone." (P4-A-W) }\end{array}$ \\
\hline & \multirow[t]{5}{*}{ Safety concerns } & $\begin{array}{l}\text { "If there was an alternative medication which has less potentially bad side effects, I would obviously } \\
\text { go for it." (PII-B-W) }\end{array}$ \\
\hline & & $\begin{array}{l}\text { "[I] knew people that had had it [warfarin] at some time or another, so I opted for that as perhaps } \\
\text { the safer option ... warfarin has been around a long time; it must be reliable. The other one, I have } \\
\text { never heard of it, do not know how long it has been around, got to be suspect." (P8-A-W) }\end{array}$ \\
\hline & & $\begin{array}{l}\text { "There were one or two people at the gym that have got exactly the same thing... They have had } \\
\text { one or two side effects with the warfarin ... with heavy bleeding and stuff like that. And I thought } \\
\text { well I do not want that really." (PI8-C-D) }\end{array}$ \\
\hline & & $\begin{array}{l}\text { "... the doctor would say 'this is a new medicine; try it and we will see how it goes'. I mean things } \\
\text { like that are not irreversible are they, you can stop using them straight away if they are not having } \\
\text { the effect or having an adverse effect." (P4-A-W) }\end{array}$ \\
\hline & & $\begin{array}{l}\text { "So that [monitoring] is what swayed me to keep taking warfarin, because I mean it is quite a serious } \\
\text { thing to be taking is not it, you know, a blood thinner .... I think it is a bit dodgy if they are going to } \\
\text { give you a tablet, though, and never call you back ... I do not know when they see you again, if at all. } \\
\text { Nobody seems to know. How do they know the dosage is right? I would probably feel safer with the } \\
\text { warfarin knowing I can go and let them check it." (P7-A-W) }\end{array}$ \\
\hline & \multirow[t]{2}{*}{ Efficacy } & $\begin{array}{l}\text { "If there's been plenty of people actually got benefit from it and I could be furnished with the volume } \\
\text { of information showing that it is beneficial for old goats like me, then I would say "Yeah give it I have } \\
\text { a try at that" 'cause it's me that's going to have the stroke if these things do not work and strokes we } \\
\text { do not want." (P8-A-W) }\end{array}$ \\
\hline & & $\begin{array}{l}\text { "I just said to him [pharmacist] 'what's with this rivaroxaban they've put me on. Is it good?' and he } \\
\text { told me. He said, 'no, it's very good. It's a new one compared to the warfarin,' he said ... I was happy } \\
\text { enough to take it." (P20-C-D) }\end{array}$ \\
\hline
\end{tabular}

(Continued)

warfarin prescribing and monitoring service. Hence, patients viewed doctors being more comfortable with prescribing warfarin. Others believed doctors had a preferred OA as it was easier to learn and work with one rather than be familiar with five different OAs.

\section{Theme 3: Oral Anticoagulants Knowledge}

This theme considers patients' knowledge about OA therapy options and how it influenced their preferences. It is presented in three subthemes: awareness of therapy options, safety concerns, and efficacy. 
Table 2 (Continued).

\begin{tabular}{|c|c|c|}
\hline Theme & Subtheme & Quotes \\
\hline \multirow[t]{8}{*}{ Impact on daily life } & \multirow[t]{4}{*}{ Lifestyle changes } & "We are very conscious of our diets here." (P8-A-W) \\
\hline & & $\begin{array}{l}\text { "We will fit the warfarin around you rather than the other way around and I think that made a } \\
\text { significant difference to how you approach taking it and it's not going to rule your life and you can } \\
\text { live a normal life without worrying about having to be tested all the time." (PIO-B-W) }\end{array}$ \\
\hline & & $\begin{array}{l}\text { "Every time before I go on holiday I inform them so we will ... try to do a test just before my holiday } \\
\text { and test after the holiday ... so always they make sure that my holidays are very limited but when I } \\
\text { go abroad ... when I fast, I tell them this is fasting month and my diet will be completely different, I } \\
\text { will be not eating and drinking for I } 8 \text { hours, I } 7 \text { hours, so they are aware of that and they try to } \\
\text { make appointment as a prior or after that change of my circumstances." (P9-B-W) }\end{array}$ \\
\hline & & "I just take one a day, and I do not bother. I think even they do not bother me". (P6-A-D). \\
\hline & \multirow[t]{4}{*}{$\begin{array}{l}\text { Monitoring and } \\
\text { dosing changes }\end{array}$} & $\begin{array}{l}\text { "If my work changes and I need to have like leave to go to hospital I would say no, this is not working } \\
\text { for me, but at the moment with my circumstances, I can control my time, I have no problem." (P9-B- } \\
\text { W) }\end{array}$ \\
\hline & & $\begin{array}{l}\text { "The only downside is that I don't know if you know the area, but where the doctor's surgery is, it's } \\
\text { at the top of a massive hill, and I have to walk up there because I have no transport, and there is no } \\
\text { bus." (P2-A-W) }\end{array}$ \\
\hline & & $\begin{array}{l}\text { "Although I was retired, and I was about } 70, \text { I was still working and traveling, and it [DOAC] suited } \\
\text { my lifestyle ... had he put me on warfarin, I would have had to go every month for check-ups, and } \\
\text { that would have seriously interfered with my lifestyle." (PI8-C-D) }\end{array}$ \\
\hline & & $\begin{array}{l}\text { "I was taking warfarin, and I was to go in every month to have the blood test and then have a } \\
\text { different dose. There were like millions of bloody tablets because I used to take like three single } \\
\text { ones, two of these, one of that, just I could not even remember them." (PI7-C-D) }\end{array}$ \\
\hline
\end{tabular}

Abbreviations: GP, general practitioner; DOAC, direct oral anticoagulant; NHS, national health service.

\section{Awareness of Therapy Options}

Before the initial consultation, some patients were already familiar with warfarin. They learned about it from their social networks (eg, family, friends) and/or professional networks (eg, working in healthcare). Some of these patients were involved in the decision-making about the choice of $\mathrm{OA}$ and used prior knowledge to inform their decisions and preferences. Few patients knew about DOACs before their consultations. During a consultation, many patients on warfarin and some on DOAC therapy said they were not given a choice and told only about one OA. Patients also discussed their lack of knowledge about therapy options, the condition, and what was happening with them, preventing them from being involved in the decision-making. These patients relied on the doctor's expertise and did not question the therapy choice made. However, patients who were experiencing issues with warfarin sought information about alternatives to warfarin from family or friends with medical education or taking an OA, print media and the Internet. Newly acquired knowledge about DOACs motivated some to ask their clinicians about switching from warfarin to DOAC therapy. Some patients who were satisfied with their prescribed therapy were not interested in learning about alternative therapy options.

\section{Safety Concerns}

Patients accepted that all medicines have side effects but would prefer a treatment with less severe or more manageable ones. Most patients sought information about a medicine's side effects profile, and some compared the side effects of warfarin and DOACs when making therapy choices. Several patients also voiced concerns about the unknown side and long-term effects of DOACs as they were new medicines. In contrast, warfarin was perceived to be a well-tested medicine with established side-effects and long-term effects and thus a safer option than a DOAC. Others viewed a DOAC as a safer option due to themselves or people in their social network having experienced side effects with warfarin, eg, bleeding. 
Some patients also questioned the safety of warfarin due to its negative connotation of being developed initially as a rat poison. Other patients admitted not knowing the side effects of OAs nor reading patient information leaflets because the prescribed medicines were assumed to be safe. Also, some patients suggested if they experienced a side effect, they could stop and change it to an alternative OA. Many patients were aware of or experienced regular monitoring with warfarin, which gave them the feeling of safety, comfort, and being looked after. Hence, they had expected the same level of monitoring with DOAC therapy. Patients had concerns and a lack of understanding about infrequent or no monitoring associated with DOAC therapy. These concerns were further amplified by patients' perception that doctors had a lack of understanding about it. Consequently, these patients felt warfarin with associated regular monitoring was a safer option.

\section{Efficacy}

Some patients talked about the effectiveness of OAs. Patients agreed that taking an OA would prevent AFrelated stroke. They wanted to be informed about new medicines as they might be better and more reliable than their currently prescribed OA therapy. Many patients did not question the effectiveness of either DOAC or warfarin therapies. However, one patient said they would need more information about a new medicine for assurance that it would be effective in their age group before considering taking it, whereas another patient thought a new medicine would have more research evidence to show its effectiveness compared to older medicines and therefore was happy to take it. Also, some patients taking DOAC therapy looked for assurance that the prescribed medicine was effective by searching for information on the Internet or consulting with their community pharmacist.

\section{Theme 4: Impact on Daily Life}

This theme describes the impact of taking OAs on patients' daily lives and how it affected their preferences for an OA. It is presented in two subthemes: lifestyle changes and monitoring and dosing changes.

\section{Lifestyle Changes}

Patients on warfarin reported adjusting their lifestyle to fit with the medicine prescribed. Patients taking warfarin were aware of certain foods interacting with warfarin and thus adjusted their diets, eg, reducing intake of vitamin $\mathrm{K}$ rich foods or alcohol. The impact of the adjustments required varied between patients. For some patients, it caused no difficulties, and they were happy to continue with warfarin. Some were also told by their clinicians that warfarin will be adapted according to their diet instead of patients needing to change their diets. Consequently, the explanation allowed them to continue with their desired diet and made the idea of taking warfarin more feasible and less disruptive to their lifestyle. Other patients described that warfarin caused issues due to their changing diets and travelling abroad. One patient described how, together with the clinicians, they agreed warfarin monitoring and dosing to manage changes of circumstances such as taking a course of antibiotics, fasting, or when going on holiday. A few patients described adjusting their holiday plans because of warfarin, eg, shorter duration, no travel abroad. Other patients stated that they declined warfarin and chose DOAC as they travelled frequently abroad. Patients taking DOACs described minimal to no impact on their lifestyle.

\section{Monitoring and Dosing Changes}

Patients described the impact of required monitoring and resulting dosing changes. As with impact on lifestyle, patients taking DOACs described minimal to no impact. The impact of the adjustments to daily lives varied between patients taking warfarin. Some patients had no issues in attending warfarin clinics but acknowledged that their situation might change in the future, for example a change in job or health status, and they would need to reconsider their OAs options. Some patients who were started on warfarin without having a different option presented thought doctors did not consider their circumstances when making prescribing decisions. These patients had challenges getting to the warfarin clinic due to lack of their own transport, reduced mobility, or unable to take time off work and therefore missed some of their appointments. Hence, some patients declined warfarin due to perceived challenges associated with regular monitoring. Also, some patients described occasionally forgetting to take the correct dose or missing a dose of warfarin, particularly as the dosing regimen frequently changed. The challenges with warfarin therapy encouraged some patients to enquire about alternative options. However, some of these patients were told they could not have DOAC therapy. Hence, they discussed strategies to lessen the impact of warfarin on their daily routines. Some asked for monitoring to be done closer to their home, eg, at a local GP practice. Others explored self-monitoring at 
home option but were told it was not available. Some described strategies to remember to take warfarin and correct dose, eg, using telephone application to record warfarin doses and set reminders when to take the dose.

\section{Discussion}

This study provides a novel contribution to the literature on DOAC uptake by exploring patients' views on the factors influencing DOAC use for stroke prevention in AF. The findings from this study provide important insights that could enable care providers to improve AF stroke prevention care. While there were a wide range of experiences and views, altogether patient narratives reveal a number of important factors for clinicians and others involved in patient care to consider. Altogether these factors influenced what OA therapy options were presented and prescribed to patients and consequently influenced patients' satisfaction with the prescribed therapy.

Our study findings indicate that barriers to DOAC use were often linked to lack of patient involvement in decision-making, which can result in patients not being aware about DOACs as a therapeutic option. Most patients on warfarin reported no or limited involvement in decisionmaking, which agreed with previous work. ${ }^{28,29}$ These patients were not informed about DOACs and had no opportunity to influence the choice of therapy prescribed. As some patients prescribed warfarin would have preferred DOAC therapy, lack of involvement in decisionmaking was a barrier for DOAC use.

Patient narratives identified that main barriers for patient involvement included some patients viewing it was the clinician's role to make decisions or did not think they could be involved due to historical ways of consulting; patient's lack of knowledge about AF or OAs and thus confidence in making-decisions; not seeing a regular clinician and lack of relationship; acute hospital admission; and limited time in consultations. These factors were consistent with previous studies identifying barriers for patients with AF involvement in decision-making around anticoagulation therapy. ${ }^{28,29}$ Lack of therapy options presented resulted in some patients having negative experiences with warfarin as it did not align with their lifestyle and thus, they experienced challenges with attending required monitoring and taking correct doses. Clinicians are in a position to engage and empower patients to become more involved in the decision-making by providing information on available therapy options, establishing their needs and preferences, and accepting patients' decision, which may or may not differ from the prescribers' preferred choice.

Several barriers to DOACs use were linked to characteristics of consultations. Firstly, limited consultation time, especially in primary care, was highlighted as a barrier. Our findings indicated that there was not enough time to discuss different OA options. Thus, patients were informed about an OA preferred by the prescriber. Consequently, prescribing decisions were seen to be influenced by prescriber preferences, which could be a barrier to DOAC use if warfarin was favoured. ${ }^{41}$ Some suggested that longer consultations were needed but noted it would not be feasible due to a shortage of clinicians in the healthcare service. Required additional time was also noted to add extra spending in already perceived costconscious healthcare system. Secondly, the timing of the initial consultation was important. Some patients discussed that in situations when they were unwell and concerned with surviving or getting better, eg, acute hospital admission, they were not able to take in the information and be part of the decision. Thus, the prescribed therapy was based on prescribers' preference. Thirdly, some patients argued that patients already established on warfarin would not be informed about DOACs due to additional clinicians' time required and the high cost of DOACs. Patients should be provided with routine reviews to be involved in reviewing prescribed therapy once their health has improved or alternative therapy, eg, DOACs, became available. The review could be performed in anticoagulation clinics led by pharmacists, which are reported to have high patient satisfaction. ${ }^{42,43}$

Participants also showed knowledge about the higher cost of DOACs compared to warfarin, which was highlighted as potential barrier to their use in the "cashstrapped NHS". Although DOACs were deemed as costeffective medicines by national guidance in England and some patients viewed them as more cost-effective than warfarin in the long term, some patients were of opinion that warfarin was favored by prescribers due to cost. They believed it was one of the reasons why they were not told about DOACs. Wider literature indicated that high cost of a medicine is a barrier to its uptake. ${ }^{25}$ Specifically, studies with DOACs showed that prescribers in countries where patients were charged for medicines through insurance were less likely to prescribe DOACs, especially for patients with lower income. ${ }^{12-17,44}$ However, to our knowledge, no such studies in countries with national health services such as UK were reported. Further research 
is needed to explore the impact of cost on the uptake of medicines deemed to be cost-effective in settings with national health service.

Consistent with prior survey research, ${ }^{30,45,46}$ patients experiencing joint or autonomous decision-making were told about more than one therapy option. They had an opportunity to voice their preferences, which were shaped by their knowledge about OAs gained from their clinicians or social network, perceived safety of OAs, and how well it would fit with their lifestyle and work arrangements. Familiarity with warfarin facilitated the choice of warfarin for some patients, whereas the unknown side and longterm effects, and lack of monitoring with DOACs raised safety concerns for others. Some patients who knew people experiencing side effects with warfarin and the inconvenience of taking it tended to choose DOAC therapy. These patients valued the lesser interference of the medicine with their daily lives more than regular monitoring which was perceived to be a safety net by some patients. Also, knowledge about DOACs motivated some patients having challenges with warfarin therapy to enquire with clinicians about switching. Thus, lack of knowledge about DOACs and safety concerns acted as barriers to DOACs use.

Reported barriers for DOAC use led to some patients receiving warfarin therapy which did not align with their daily lives. Some patients reported it causing undue stress and non-adherence. Thus, addressing the identified barriers for DOACs use and patient involvement in decision-making, could potentially achieve better therapy adherence, patient satisfaction with the consultation and therapy, and overall health. ${ }^{47}$

\section{Implications for Practice}

Our study findings outlined barriers to DOAC use and highlighted importance and challenges for patient involvement in decision-making. In order to improve care for patients with $\mathrm{AF}$, we recommend for health organizations and clinicians to consider:

- Developing and dedicating a team of healthcare professionals with expertise in anticoagulation within GP practice to initiate OA therapy and provide continuity of ongoing care to build rapport with a patient.

- Lengthening consultation times (especially in primary care) when the decision to start an anticoagulation is being made to facilitate discussion of therapy options and address patients' concerns.

- Providing periodic review of patients' satisfaction with their current prescribed therapy and the option to consider alternative therapy options, which potentially could identify and resolve difficulties patients experience that clinicians might not be aware of.

- Tailoring prescribed therapy to patients' preferences to ensure the therapy fits with their daily lives.

\section{Strengths and Limitations}

The findings and transferability of findings to different settings and patient groups should be considered in the context of the study strengths and limitations. The main strength of this study was moderate sample size and recruitment of participants from three health economies with different anticoagulation service provision models. Also, semi-structured in-depth interviews provided rich and varied lived experiences, enabling greater insight into potential barriers for DOACs use. Lastly, data analysis robustness was ensured by more than one author being involved in the process and development of themes and subthemes.

We note the sample comprised almost exclusively of White British participants and more male patients were recruited, which is not fully representative of the wider population of the UK. However, AF is more prevalent in men. ${ }^{2}$ Clinical characteristics of patients (eg, comorbidities) were not collected, which could have provided an extra dimension for interpretation of patients' perspectives according to their personal stroke risk. The study also relied on participants' accounts of consultations when OA therapy was initiated, which could be affected by recall bias. Lastly, participant validation, which could have increased internal validity of results, was not undertaken. Instead, discussions with PPI advisory group were carried out to ensure data represented patients' experiences.

\section{Conclusion}

This study has presented an in-depth evaluation of patients' perspectives on potential barriers to DOAC use for stroke prevention in AF. Our findings suggested that perceived high DOAC cost, consultation time constraints, varying local services, lack of knowledge about DOACs, safety concerns about OAs, lack of patient involvement in decision-making, and prescribing habits favoring established therapy were barriers to DOAC use. Lack of 
consideration of OA therapy impact on daily lives and opportunity for patients to voice therapy preferences resulted in some patients being dissatisfied with the prescribed therapy and management of difficulties caused by the prescribed medicine. Greater patient involvement in decision-making could prevent and resolve difficulties encountered by some patients and increase DOAC use.

\section{Supplementary Material}

Supplementary file 1 Interview guide

Supplementary file 2 Description of health economies studied in the study.

\section{Acknowledgments}

The authors would like to thank the patients who generously gave their time to be interviewed, the Patient and Public Involvement advisory group for all their support throughout this study and the direct care team members who helped with the recruitment of participants. Also, we would like to thank the Pharmacy Research UK and Leeds Teaching Hospitals NHS Trust for the grant funding that enabled conduction of the study.

\section{Funding}

Financial support for this study was provided entirely by a grant from the Pharmacy Research UK (PRUK-2018-GA1-KM) and Leeds Teaching Hospitals NHS Trust. The funding agreement ensured the authors' independence in designing the study, interpreting the data, writing, and publishing the report. The views expressed are those of the author and not necessarily those of Pharmacy Research UK or Leeds Teaching Hospitals NHS Trust.

\section{Disclosure}

$\mathrm{KM}, \mathrm{SR}, \mathrm{BF}, \mathrm{MR}$, DP have no conflicts of interest to declare for this work. KS is employed by one of the sponsors of the study, reports grants from the Pharmacy Research UK and Leeds Teaching Hospitals NHS Trust during the conduct of the study, and reports no other potential conflicts of interest for this work.

\section{References}

1. Chugh SS, Havmoeller R, Narayanan K, et al. Worldwide epidemiology of atrial fibrillation: a Global Burden of Disease 2010 study Circulation. 2014;129(8):837-847. doi:10.1161/CIRCULATION AHA.113.005119

2. Lippi G, Sanchis-Gomar F, Cervellin G. Global epidemiology of atrial fibrillation: an increasing epidemic and public health challenge. Int $J$ Stroke. 2020;1-5. doi:10.1177/1747493019897870
3. Friberg L, Rosenqvist M, Lindgren A, et al. High prevalence of atrial fibrillation among patients with ischemic stroke. Stroke. 2014;45:2599-2605. doi:10.1161/STROKEAHA.114.006070

4. The National Institute for Health Care and Excellence (NICE). Atrial fibrillation: management (CG180); 2020. Available from: https:// www.nice.org.uk/guidance/cg180. Accessed May 26, 2020.

5. Cowan JC, Wu J, Hall M, et al. A 10-year study of hospitalized atrial fibrillation-related stroke in England and its association with uptake of oral anticoagulants. Eur Heart J. 2018;39(32):2975-2983. doi:10.1093/eurheartj/ehy411

6. Kirchhof P, Benussi S, Kotecha D, et al. ESC guidelines for the management of atrial fibrillation developed in collaboration with EACTS. Eur Heart J. 2016;37:2893-2962.

7. The Task Force for the Management of Atrial Fibrillation of the European Society of Cardiology (ESC). Guidelines for the management of atrial fibrillation. Eur Heart J. 2011;6:240-429.

8. The Task Force for the management of atrial fibrillation of the European Society of Cardiology (ESC). ESC guidelines for the management of atrial fibrillation developed in collaboration with EACTS. Eur Heart J. 2016;37:2893-2962.

9. Bai Y, Guo SD, Deng H, et al. Effectiveness and safety of oral anticoagulants in older patients with atrial fibrillation: a systematic review and meta-regression analysis. Age Ageing. 2018;47(1):9-17. doi:10.1093/ageing/afx103

10. Loo SY, Dell'Aniello S, Huiart L, et al. Trends in the prescription of novel oral anticoagulants in UK primary care. Br J Clin Pharmacol. 2017;83(9):2096-2106. doi:10.1111/bcp.13299

11. ABPI SAFI. One year on: why patients still having unnecessary AFrelated strokes? 2016. Available from: http://www.abpi.org.uk/media centre/newsreleases/2016/Documents/Embargo9May_ABPI_ OneYearOn_FINALREPORT.pdf. Accessed February 17, 2017.

12. AbuDagga A, Stephenson JJ, Fu AC, et al. Characteristics affecting oral anticoagulant therapy choice among patients with non-valvular atrial fibrillation: a retrospective claims analysis. BMC Health Serv Res. 2014;14:310. doi:10.1186/1472-6963-14-310

13. Baik SH, Hernandez I, Zhang Y. Evaluating the initiation of novel oral anticoagulants in medicare beneficiaries. J Manag Care Spec Pharm. 2016;22(3):281-292. doi:10.18553/jmcp.2016.22.3.281

14. Huang C, Siu M, Vu L, et al. Factors influencing doctors' selection of dabigatran in non-valvular atrial fibrillation. $J$ Eval Clin Pract. 2013;19:938-943. doi:10.1111/j.1365-2753.2012.01886.x

15. Patel PA, Zhao X, Fonarow GC, et al. Novel oral anticoagulant use among patients with atrial fibrillation hospitalized with ischemic stroke or transient ischemic attack. Circ Cardiovasc Qual Outcomes. 2015;8(4):383-392. doi:10.1161/CIRCOUTCOM ES.114.000907

16. Potpara TS, Trendafilova E, Dan GA, et al. The patterns of Nonvitamin K Antagonist Oral Anticoagulants (NOACs) use in patients with atrial fibrillation in seven Balkan countries: a report from the BALKAN-AF survey. Adv Ther. 2017;34:2043-2057. doi:10.1007/ s12325-017-0589-5

17. Salmasi S, Kapanen AI, Kwan L, et al. Atrial fibrillation patients' experiences and perspectives of anticoagulation therapy changes. Res Social Adm Pharm. 2020;16(10):1409-1415. doi:10.1016/j. sapharm.2020.01.004

18. Anderson TS, Lo-Ciganic WH, Gellad WF, et al. Patterns and predictors of physician adoption of new cardiovascular drugs. Healthcare. 2018;6:33-40. doi:10.1016/j.hjdsi.2017.09.004

19. Brais C, Larochelle J, Turgeon MH, et al. Predictors of direct oral anticoagulants utilization for thromboembolism prevention in atrial fibrillation. J Pharm Pharm. 2017;20:8-14.

20. Zhang Y, Méndez SJ, Scott A. Factors affecting general practitioners' decisions to adopt new prescription drugs - cohort analyses using Australian longitudinal physician survey data. BMC Health Serv Res. 2019;19(1):94. doi:10.1186/s12913-019-3889-4 
21. Clarkesmith DE, Lip GHY, Lane DA. Patients' experiences of atrial fibrillation and non-vitamin $\mathrm{K}$ antagonist oral anticoagulants (NOACs), and their educational needs: a qualitative study. Thromb Res. 2017;153:19-27. doi:10.1016/j.thromres.2017.03.002

22. Murphy A, Kirby A, Bradley C. Knowledge is power: general practitioners prescribing of new oral anticoagulants in Ireland. BMC Res Notes. 2018;11:478-484. doi:10.1186/s13104-018-3597-x

23. Tanislav C, Allendorfer J, Pfeilschifter W, et al. One decade of oral anticoagulation in stroke patients: results from a large country-wide hospital-based registry. Int $J$ Stroke. 2018;13(3):308-312. doi:10.1177/1747493017733928

24. Lo-Ciganic WH, Gellad WF, Huskamp HA, et al. Who were the early adopters of dabigatran? An application of group-based trajectory models. Med Care. 2016;54(7):725-732. doi:10.1097/ MLR.0000000000000549

25. Medlinskiene K, Tomlinson J, Marques I, et al. Barriers and Facilitators to Implementation of New Medicines into Clinical: A Systematic Review. Bradford: University of Bradford; 2020.

26. Department of Health. The NHS Constitution: the NHS belongs to us all; 2015. Available from: https://www.gov.uk/government/uploads/ system/uploads/attachment_data/file/480482/NNH_Constitution_ WEB.pdf. Accessed March 17, 2017.

27. Loughlin $M$, Buetow $S$, Cournoyea $M$, et al. Interactions between persons - knowledge, decision making, and the co-production of practice. J Eval Clin Pract. 2019;25:911-920. doi:10.1111/jep.13297

28. Borg CX, Shaw R, Lane DA. Patients' and health professionals' views and experiences of atrial fibrillation and oral-anticoagulation therapy: a qualitative meta-synthesis. Patient Educ Couns. 2012;88 (2):330-337. doi:10.1016/j.pec.2012.05.011

29. Medlinskiene K, Petty D, Richardson S, et al. Are patients with nonvalvular atrial fibrillation involved in decision-making about oral anticoagulants? A literature review. IJPP. 2018;26(1 Suppl):S42S43.

30. Choi JC, DiBonaventura M, Kopenhafer L, et al. Survey of the use of warfarin and the newer anticoagulant dabigatran in patients with atrial fibrillation. Patient Prefer Adherence. 2014;8:167-177. doi:10.2147/PPA.S56187

31. Tomlinson J, Medlinskiene K, Cheong V, et al. Patient and public involvement in designing and conducting doctoral research: the whys and the hows. Res Involv Engagem. 2019;5(23). doi:10.1186/s40900019-0155-1

32. Coyne IT. Sampling in qualitative research. Purposeful and theoretical sampling; merging or clear boundaries? J Adv Nurs. 1997;26 (3):623-630. doi:10.1046/j.1365-2648.1997.t01-25-00999.x

33. Patton MQ. Qualitative Research and Evaluation Methods. London: SAGE publications; 2015.

34. Dantas GC, Thompson BV, Manson JA, et al. Patients' perspectives on taking warfarin: qualitative study in family practice. BMC Fam Pract. 2004;5:15-24. doi:10.1186/1471-2296-5-15
35. Borg XC, Shaw RL, Lane DA. Patients' and physicians' experiences of atrial fibrillation consultations and anticoagulation decision-making: a multi-perspective IPA design. Psychol Health. 2016;31(4):436455. doi:10.1080/08870446.2015.1116534

36. Guest G, Bunce A, Johnson L. How many interviews are enough? An experiment with data saturation and variability. Field Methods. 2006;18(1):59-82. doi:10.1177/1525822X05279903

37. Ritchie J, Lewis J, Nicholls C, et al. Qualitative Research Practice: A Guide for Social Science Students and Researchers. London: SAGE publications; 2014.

38. Gale NK, Heath G, Cameron E, et al. Using the framework method for the analysis of qualitative data in multi-disciplinary health research. BMC Medical Research Methodology. 2013;13(1):117125. doi:10.1186/1471-2288-13-117

39. Parkinson S, Eatough V, Holmes J, et al. Framework analysis: a worked example of a study exploring young people's experiences of depression. Qual Res Psychol. 2016;13(2):109-129. doi:10.1080/ 14780887.2015.1119228

40. Nowell LS, Norris JM, White DE, et al. Thematic analysis: striving to meet the trustworthiness criteria. Int J Qual Methods. 2017;16 (1):1-13. doi:10.1177/1609406917733847

41. Pritchett RV, Clarke JL, Jolly K, et al. Clinicians' views and experiences of prescribing oral anticoagulants for stroke prevention in atrial fibrillation: a qualitative meta-synthesis. PLoS One. 2020;15(5): e0232484. doi:10.1371/journal.pone.0232484

42. Beyene K, Chan AHY, Bandreddi NST, et al. Patient satisfaction with community pharmacist-led anticoagulation management services and its relationship with patient characteristics in New Zealand. Int J Clin Pharm. 2020. doi:10.1007/s11096-020-01124-y

43. Ingram SJ, Kirkdale CL, Williams S, et al. Moving anticoagulation initiation and monitoring services into the community: evaluation of the Brighton and Hove community pharmacy service. BMC Health Serv Res. 2018;18(1):91. doi:10.1186/s12913-018-2901-8

44. Kirley K, Goutham R, Bauer V, et al. The role of NOACs in atrial fibrillation management: a qualitative study. $J$ Atr Fibrillation. 2016;9(1):1416. doi:10.4022/jafib.1416

45. Andrade JG, Krahn AD, Skanes AC, et al. Value and preferences of physicians and patients with nonvalvular atrial fibrillation who receive oral anticoagulation therapy for stroke prevention. Can $J$ Cardiol. 2017;32:747-753. doi:10.1016/j.cjca.2015.09.023

46. Baicus C, Balanescu P, Zeh S, et al. Characteristics of shared decision making in Romania from the patient perspective: a cross-sectional multicentric study. J Eval Clin. 2019;25:1152-1159. doi:10.1111/ jep. 13257

47. Shay LA, Lafata JE. Where is the evidence? A systematic review of shared decision making and patient outcomes. Med Decis Making. 2015;35(1):114-131. doi:10.1177/0272989X14551638
Patient Preference and Adherence

\section{Publish your work in this journal}

Patient Preference and Adherence is an international, peer-reviewed, open access journal that focusing on the growing importance of patient preference and adherence throughout the therapeutic continuum. Patient satisfaction, acceptability, quality of life, compliance, persistence and their role in developing new therapeutic modalities and compounds to optimize clinical outcomes for existing disease states are major areas of interest for the journal. This journal has been accepted for indexing on PubMed Central. The manuscript management system is completely online and includes a very quick and fair peer-review system, which is all easy to use. Visit http:// www.dovepress.com/testimonials.php to read real quotes from published authors. 